\title{
Lactoferrin interacts with bile acids and increases fecal cholesterol excretion in rats
}

\begin{tabular}{|c|c|}
\hline Journal: & Biochemistry and Cell Biology \\
\hline Manuscript ID & bcb-2016-0052.R3 \\
\hline Manuscript Type: & Article \\
\hline Date Submitted by the Author: & 23-Sep-2016 \\
\hline Complete List of Authors: & $\begin{array}{l}\text { Nakamura, Kanae; Lion Corporation, Research and Development } \\
\text { Headquarters } \\
\text { Morishita, Satoru; Lion Corporation, Research and Development } \\
\text { Headquarters; The University of Tokyo, "Food for Life", Organization for } \\
\text { Interdisciplinary Research Projects } \\
\text { Ono, Tomoji; Lion Corporation, Research and Development Headquarters; } \\
\text { Yokohama City University, Advanced Medical Research Center } \\
\text { Murakoshi, Michiaki; Lion Corporation, Research and Development } \\
\text { Headquarters; Yokohama City University, Advanced Medical Research } \\
\text { Center; Kyoto Prefectural University of Medicine } \\
\text { Sugiyama, Keikichi; Lion Corporation, Research and Development } \\
\text { Headquarters; Ritsumeikan University, Research Organization of Science } \\
\text { and Engineering } \\
\text { Kato, Hisanori; The University of Tokyo, "Food for Life", Organization for } \\
\text { Interdisciplinary Research Projects } \\
\text { Ikeda, Ikuo; Tohoku University, Laboratory of Food and Biomolecular } \\
\text { Science, Department of Food Function and Health, Graduate School of } \\
\text { Agricultural Science } \\
\text { Nishino, Hoyoku; Kyoto Prefectural University of Medicine }\end{array}$ \\
\hline Keyword: & lactoferrin, cholesterol, bile acid, rats, hypercholesterolemia \\
\hline
\end{tabular}




\section{Title page}

Lactoferrin interacts with bile acids and increases fecal cholesterol excretion in rats

Kanae Nakamura ${ }^{1}$; Satoru Morishita ${ }^{1,2}$; Tomoji Ono ${ }^{1,3}$; Michiaki Murakoshi ${ }^{1,3,4}$; Keikichi

Sugiyama $^{1,5}$; Hisanori Kato ${ }^{2}$; Ikuo Ikeda ${ }^{6}$; and Hoyoku Nishino ${ }^{4}$

${ }^{1}$ Research and Development Headquarters, Lion Corporation, 100 Tajima, Odawara, Kanagawa

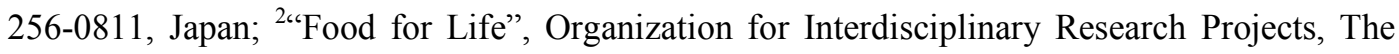

University of Tokyo, 1-1-1 Yayoi, Bunkyo-ku, Tokyo 113-8657, Japan; ${ }^{3}$ Advanced Medical

Research Center, Yokohama City University, 3-9 Fukuura, Kanazawa-ku, Yokohama,

Kanagawa 236-0004, Japan; ${ }^{4}$ Kyoto Prefectural University of Medicine, Kawaramachi-Hirokoji,

Kamigyou-ku, Kyoto 602-0841, Japan; ${ }^{5}$ Research Organization of Science and Engineering,

Ritsumeikan University, 1-1-1 Nojihigashi, Kusatsu, Shiga 525-8577, Japan; ${ }^{6}$ Laboratory of

Food and Biomolecular Science, Department of Food Function and Health, Graduate School of

Agricultural Science, Tohoku University, 1-1 Amamiya-machi, Tsutsumidori, Aoba-ku, Sendai,

Miyagi 981-8555, Japan

This study was funded by Lion Corporation and no specific grant was received from any

funding agency in the public, commercial, or not-for-profit sectors with regards to this study. 


\section{Abstract}

Lactoferrin (LF) is a multifunctional cationic protein (pI 8.2 to 8.9 ) in mammalian milk. We previously reported that enteric-LF prevented hypercholesterolemia and atherosclerosis in a diet-induced atherosclerosis model using Microminipig ${ }^{\mathrm{TM}}$, although the underlying mechanisms remain unclear. Because LF is assumed to electrostatically interact with bile acids to inhibit intestinal cholesterol absorption, LF could promote cholesterol excretion. In this study, we assessed the interaction between LF and taurocholate in vitro and the effect of LF on cholesterol excretion in rats. The binding rate of taurocholate to LF was significantly higher than that to transferrin ( $\mathrm{pI} 5.2$ to 6.3). When rats were administered a high-cholesterol diet (HCD) containing 5\% LF, LF was detected using ELISA in the upper small intestine from 7.5 to $60 \mathrm{~min}$ after the administration. Rats were fed one of the following diets: Control, HCD, or HCD $+5 \%$ LF for 21 days. Fecal neutral steroids and hepatic cholesterol levels in the HCD group were significantly higher than those in the Control group. The addition of LF to a HCD significantly increased fecal neutral steroids levels $(22 \%$ increase, $p<0.05)$ and reduced hepatic cholesterol levels $(17 \%$ decrease, $p<0.05)$. These parameters were inversely correlated $(\mathrm{R}=-0.63, p<$ 0.05). These results suggest that LF promotes cholesterol excretion via interactions with bile acids. 
Keywords: lactoferrin, cholesterol, bile acid, rats, hypercholesterolemia

\section{Introduction}

Atherosclerosis, a well-known risk factor for cardiovascular disease, is characterized by the accumulation of lipids within macrophages, which promote inflammation and the formation of atheroma plaques. The development of atherosclerotic cardiovascular disease is strongly associated with serum levels of low-density lipoprotein cholesterol and has been identified as the primary risk factor for atherosclerotic cardiovascular disease (Choy et al. 2004; members 2014; Roy 2014). Therefore, it is important to prevent the accumulation of serum low-density lipoprotein cholesterol. The use of functional food factors as dietary supplements that are safe for daily consumption presents an attractive approach to prevent hypercholesterolemia and atherosclerosis.

Lactoferrin (LF) is an iron-binding cationic protein that is abundant in breast milk and plays important roles in many physiological functions by acting as an antibacterial, antiviral, immunostimulatory, and antioxidant, in addition to its potential to prevent cancer (Harmsen et al. 1995; Kozu et al. 2009; Shoji et al. 2007; Tomita et al. 1991; Vogel 2012; Zimecki et al. 1998). And besides these actions, several researchers have reported the beneficial effects of LF on lipid metabolism (Moreno-Navarrete et al. 2009; Morishita et al. 2013; Morishita et al. 2015; Takeuchi et al. 2004; Yagi et al. 2008). In accordance with these studies, we found that 
enteric-coated LF significantly reduced areas of visceral fat in a double-blind clinical trial (Ono et al. 2010). As a possible mechanism, we further reported that LF promoted anti-adipogenic activities of pre-adipocytes derived from rat mesenteric fat tissue and lipolytic activities of mature adipocytes differentiated from preadipocytes (Ikoma-Seki et al. 2015; Ono et al. 2013; Ono et al. 2011).

Several beneficial effects of LF on cholesterol-related disorders have also been reported. For example, Takeuchi et al. (2004) reported that LF administration reduced hepatic cholesterol levels in mice. Our group also found that LF ameliorated hypercholesterolemia in mice (Suzuki, N., unpublished reports). We further demonstrated that enteric LF inhibited the development of hypercholesterolemia and atherosclerosis induced by a high-fat and high-cholesterol diet in MicrominipigTM (MMPig) (Morishita et al.2016), which has cholesterol profiles similar to those of humans (i.e., dominance of low-density lipoprotein cholesterol rather than high-density lipoprotein cholesterol), unlike rodents (Kawaguchi et al. 2011).

Lowering of cholesterol is considered the primary approach to prevent atherogenesis (Choy et al. 2004; members 2014; Roy 2014). Cholesterol is absorbed in the small intestine via solubilization with bile acids and uptakes into micelles (Wilson and Rudel 1994). Various studies reported that bile acid-binding cationic food factors, such as chitosan and soy protein, 
promote the lowering of serum cholesterol levels (Bokura and Kobayashi 2003; Carroll 1991; Mhurchu et al. 2004). These food factors are also reported to reduce the micellar solubility of cholesterol and promote fecal cholesterol excretion in cholesterol-fed rats (Gallaher et al. 2000; Liu et al. 2008; Nagaoka et al. 1999). Shimazaki et al. (1993) reported that the isoelectric point of LF was 8.2 to 8.9, and Baker and Baker (2009) reported that the surface of LF molecules contained notable positively charged regions. These studies suggested that cationic LF electrostatically interacts with anionic bile acids in the small intestine, which may inhibit cholesterol absorption, resulting in the prevention of hypercholesterolemia and atherosclerosis. However, the effect of LF on cholesterol absorption remains poorly understood. Therefore, the aims of the present study were to assess the interactions between LF and taurocholate in vitro and the effects of LF on cholesterol excretion in rats.

\section{Materials and Methods}

\section{Materials}

Bovine LF was purchased from FrieslandCampina (Amersfoort, The Netherlands). According to the certificate of analysis, typical protein purity was $98 \%$. Cholesterol and sodium taurocholate were purchased from Wako Pure Chemical Industries, Ltd. (Tokyo, Japan). Casein and transferrin was purchased from Sigma-Aldrich Corporation (St. Louis, MO, USA). 
Interaction between $L F$ and taurocholate in vitro

The experiment was performed according to the methods of Huth et al. (2000). LF (0, 5, and 10 $\mathrm{mg} / \mathrm{mL})$ or transferrin $(10 \mathrm{mg} / \mathrm{mL})$ was incubated with $0.5 \mathrm{mg} / \mathrm{mL}$ sodium taurocholate in $2 \mathrm{~mL}$ of phosphate buffer $(\mathrm{pH} 6.5)$ at $37^{\circ} \mathrm{C}$ for $2 \mathrm{~h}$ with shaking. Unbound taurocholate was separated by ultrafiltration using a 10K MWCO membrane (Merck Millipore Corp., Darmstadt, Germany) and measured with the Total Bile Acids Test Wako kit (Wako Pure Chemical Industries, Ltd.).

\section{Animals and Diets}

All animal experiments were carried out according to protocols approved by the Institutional Animal Care and Use Committee of Lion Corporation (Odawara, Japan). Six-week-old male Sprague-Dawley rats were purchased from Japan SLC, Inc. (Shizuoka, Japan) and acclimated for 3-8 days in a temperature-controlled room under a 12-h light/dark cycle and housed individually in stainless-steel cages. A modified AIN-93G diet (30\% fat, $20 \%$ protein, $50 \%$ carbohydrate) was purchased from EPS EKISHIN Co., Ltd. (Tokyo, Japan) and used as the basal diet. The composition of the basal diet is shown in Table 1. The basal diet supplemented with $5 \%$ casein (Control), $5 \%$ casein plus $0.3 \%$ cholesterol (HCD), and $5 \%$ LF plus $0.3 \%$ cholesterol $(\mathrm{HCD}+\mathrm{LF})$ were used as experimental diets. The compositions of the experimental 
diets are shown in Table 2.

Effect of LF on fecal neutral steroid excretion in rats

Three groups, Control, HCD, or HCD + LF groups received 8 rats each with matched mean body weights after the acclimation period and each rat was fed the corresponding diet for 21 days. During the experimental period, all rats were allowed free access to diets and water. The feces of each rat were collected on the last 2 days of the experimental period and then lyophilized and stored at $-80^{\circ} \mathrm{C}$ until analysis. On the final day, blood was collected from the abdominal vein under isoflurane anesthesia without starvation. After exsanguination, livers were immediately excised. The serum samples and livers were stored at $-80^{\circ} \mathrm{C}$ until analysis.

\section{Biochemical analysis}

Serum levels of total cholesterol and triglyceride were analyzed using the Cholesterol E-test Wako kit and Triglyceride E-test Wako kit, respectively (Wako Pure Chemical Industries, Ltd.). Hepatic lipids were extracted with chloroform/methanol $(2: 1, \mathrm{v} / \mathrm{v})$ according to the method of (Folch et al. 1957). Extracted lipids were saponified in ethanolic $\mathrm{KOH}$ and nonsaponifiable lipids were extracted from the alkaline mixture with chloroform/methanol $(2: 1, \mathrm{v} / \mathrm{v})$. Fecal steroids were extracted with hot ethanol. Quantification of hepatic cholesterol and fecal neutral 
steroids was performed by gas chromatography (7890A instrument; Agilent Technologies, Santa Clara, CA, USA) using a HP-5 column (Agilent Technologies). 5 $\alpha$-Cholestane (SigmaAldrich) was used as an internal control. Fecal bile acids were analyzed using the Total Bile Acids Test Wako kit (Wako Pure Chemical Industries, Ltd.).

Quantification of $L F$ in the proximal halves of the small intestine

After acclimation, the rats were fed HCD + LF for 4 days ad libitum and then fasted for $16 \mathrm{~h}$. After fasting, rats $(n=6)$ were fed $4 \mathrm{~g}$ of $\mathrm{HCD}+\mathrm{LF}$ at the beginning of a dark period. At 7.5, 15,30 , and $60 \mathrm{~min}$ from the beginning of refeeding, the rats were sacrificed under anesthesia and the contents in the proximal halves of the small intestine were collected, according to the methods described by (Ono et al. 2011). In the Control group, rats $(n=4)$ were fed $4 \mathrm{~g}$ of HCD and sacrificed under anesthesia at $30 \mathrm{~min}$ from the beginning of refeeding. Collected samples were stored at $-80^{\circ} \mathrm{C}$ until analysis. The amount of $\mathrm{LF}$ in the small intestine was quantified using an enzyme-linked immunosorbent assay (ELISA; Bethyl Laboratories, Montgomery, TX, USA).

Statistical analysis

Data are presented as means \pm standard deviations. Basically, data were compared using 
one-way analysis of variance (ANOVA) and the post-hoc Tukey-Kramer test. A probability $(p)$ value of $<0.05$ was considered statistically significant. Data were analyzed using JMP software ver. 11.2.0 (SAS Institute, Inc., Cary, NC, USA). Correlations between hepatic cholesterol levels and fecal neutral steroids excretion levels were identified using the Pearson product-moment correlation coefficient.

\section{Results}

Interaction between $L F$ and taurocholate in vitro

The interaction between LF and taurocholate, which is a major component of bile acids in rodents (Siow et al. 1991), was investigated in this study. The percentage of LF-bound taurocholate (unfiltered taurocholate) was significantly increased by the addition of LF at 5 $\mathrm{mg} / \mathrm{mL}$ or more, as compared with that in the non-additive group. The percentage of LF-bound taurocholate was significantly higher than that of transferrin-bound taurocholate when incubated at the same concentration. The percentage of LF-bound taurocholate at 5 and 10 $\mathrm{mg} / \mathrm{mL}$ LF were $4.79 \pm 1.13 \%$ and $12.20 \pm 1.35 \%$, respectively.

LF levels in the proximal halves of the small intestine after oral administration

Immunoreactive LF was detected in the content of the proximal intestine from 7.5 to $60 \mathrm{~min}$ 
after LF administration (Table 3). The maximum amount of LF (1.5 mg/proximal intestine) was detected at $7.5 \mathrm{~min}$ and the amount of LF decreased in a time-dependent manner. In the Control group, the amount of LF in the proximal intestine was under the detection limit $(<0.0041$ $\mathrm{mg} /$ proximal intestine).

\section{Effect of LF on fecal neutral steroid excretion in rats}

There was no significant difference in body weight gain or food intake over the 21-day feeding period among the Control, HCD, and HCD + LF groups (Table 4). There were no differences in serum concentrations of total cholesterol and triglyceride among the three groups (Table 5). The administration of HCD significantly increased hepatic cholesterol levels compared with those in the Control group. The addition of LF to HCD significantly decreased hepatic cholesterol levels compared with those in the HCD group $(17 \%$ decrease, $p=0.0124)$. As shown in Table 6 , there were no significant differences in fecal weight among the three groups. The excreted levels of fecal bile acids and fecal neutral steroids in the HCD group were significantly higher than those in the Control group. The addition of LF to HCD had no effect on excreted levels of fecal bile acids, whereas LF significantly increased the excreted levels of fecal neutral steroids compared with those in the HCD group (22\% increase, $p=0.0189)$. LF administration exhibited a significant increase in fecal cholesterol excretion compared with the HCD group (33\% increase, 
$p=0.0341$ ) but had no effect on fecal coprostanol excretion. As shown by the data in Fig. 2, there were significant inverse correlations between hepatic cholesterol levels and excreted levels of fecal neutral steroids $(\mathrm{R}=-0.63, p<0.05)$.

\section{Discussion}

In our previous study, LF was administered to MMPigs using enteric capsules to evaluate its potential against hypercholesterolemia and atherosclerosis (Morishita et al. 2016). However, it is difficult to administer enteric LF to rats because there is no commercially available enteric formulation. Therefore, LF was administered to rats in this study by dietary supplementation.

It is well known that the administration of high-cholesterol diet to rats increases the excretion of fecal steroids and induces hepatic cholesterol accumulation. Various researchers have reported that food factors which inhibit cholesterol absorption, such as catechins, dietary fibers, and soy protein, increase fecal steroid excretion, and decrease hepatic cholesterol levels in high-cholesterol diet fed rats (Arjmandi et al. 1992; Gallaher et al. 2000; Kobayashi et al. 2005; Muramatsu et al. 1986; Nagaoka et al. 1999). The present study revealed that LF promoted fecal cholesterol excretion in rats fed HCD (Table 6), suggesting that LF inhibited cholesterol absorption in the small intestine. The negative correlation between hepatic cholesterol levels and excretion levels of fecal neutral steroids was also observed in this study 
(Fig. 2). This observation is consistent with the results of previous publication investigating the effect of soy and potato peptide on lipid homeostasis (Liyanage et al. 2009). Taken together with our study, it is suggested that the increase in cholesterol excretion led to a reduction in hepatic cholesterol levels. Contrary to the findings of this study, Takeuchi et al. (2004) reported that the administration of $1 \%$ LF did not affect fecal cholesterol excretion by mice fed a $1 \%$ cholesterol diet. In this study, we administered a diet containing $5 \%$ LF and $0.3 \%$ cholesterol to rats. Therefore, the difference in fecal cholesterol excretion compared with that in previous studies may be due to differences in experimental conditions, such as animal species and compositions of test diets.

The results of this study showed that LF interacted with taurocholate in vitro (Fig. 1), whereas LF did not affect the excretion of fecal bile acids (Table 6). It is generally recognized that orally administered proteins are hydrolyzed in the gastrointestinal tract. Although LF was detected using ELISA in the proximal region of the rat small intestine in this study (Table 3), Kuwata et al. (2001) reported that orally administered LF was degraded more intensively in the distal region, where bile acids are reabsorbed, compared with the proximal region of the small intestine. This report suggests that intensively degraded LF might fail to interact with bile acids and allow reabsorption of bile acids in the distal region.

In the small intestine, cholesterol is solubilized in bile acid micelles and diffuses to the 
small intestinal epithelial cells across the unstirred water layer. Subsequently, cholesterol is released from micelles and absorbed into the small intestinal epithelial cells (Wilson and Rudel 1994). Cholesterol absorption primarily occurs in the proximal region of the small intestine, which has a high expression of the cholesterol transporter Niemann-Pick C1 Like1 (NPC1L1) (Altmann et al. 2004). In this study, LF was detected in the proximal halves of the small intestine from 7.5 to 60 min after LF administration using ELISA (Table 3). Previously, we demonstrated that the digestion of LF with trypsin yielded relatively large fragments and digestion with pepsin yielded very small fragments (Ono et al. 2011). We confirmed that the ELISA kit could detect intact LF and trypsin-degraded LF but not pepsin-degraded LF (data not shown). Therefore, relatively large fragments of LF seemed to reach the proximal regions of the rat small intestine after oral administration. We further demonstrated an interaction between LF and taurocholate in an in vitro study (Fig. 1). Bile acid-binding food factors such as soy protein are reported to reduce micellar solubility of cholesterol and to suppress intestinal cholesterol absorption (Nagaoka et al. 1999). Altogether, the present study implies the possibility that the interaction between LF and bile acids lead to the decrease of micellar solubility of cholesterol and the inhibition of intestinal cholesterol absorption. It should be noted that the cationic peptide lactoferricin is produced by pepsin following the oral administration of LF (Tomita et al. 2009). As lactoferricin (3 $\mathrm{kDa})$ is smaller than full-length $\mathrm{LF}(80 \mathrm{kDa})$, binding of $\mathrm{LF}$ and 
lactoferricin to micelles could differ and this difference may influence the inhibitory efficacy of intestinal cholesterol absorption. Further studies are required to identify the functional form of LF that best promotes cholesterol excretion.

An interaction between LF and taurocholate was observed (Fig. 1) under the similar conditions as a previous report using dietary fibers (Huth et al. 2000). The concentration of taurocholate in the present study (approximately $1 \mathrm{mM}$ ) was lower than the critical micellar concentration (3-12 mM) (Meyerhoffer and McGown 1990), whereas the concentration of bile acids in the small intestine was higher than the critical micellar concentration of bile acids, which form micelles in the small intestine (Gunness and Gidley 2010). Moreover, other components, such as phospholipids, fatty acids, and monoglycerides, are involved in the micellar solubility of cholesterol in the small intestine. Therefore, it is necessary to evaluate the effect of LF on the micellar solubility of cholesterol using a model micellar system, which reflects the actual environment of the small intestine.

To clarify the mechanisms underlying the actions of LF on cholesterol excretion, other factors affecting cholesterol absorption should be explored. Sterol transporters, such as ATP-binding cassette G5, ATP-binding cassette G8, and NPC1L1, are recognized as the primary factors affecting cholesterol absorption. Several studies reported that food factors, such as soy protein, barley, and sesamin, regulate the expression of these sterol transporters to 
increase fecal cholesterol excretion (Gonzalez-Granillo et al. 2012; Hoang et al. 2011; Liang et al. 2015). Hence, these factors should be investigated in a future study to elucidate the mechanism underlying the actions of LF.

In summary, we have revealed a promotive effect of LF on cholesterol excretion and an interaction between LF and taurocholate. The interaction between LF and bile acids possibly contribute to the promotive effect of LF on cholesterol excretion.

\section{References}

Altmann, S.W., Davis, H.R., Jr., Zhu, L.J., Yao, X., Hoos, L.M., Tetzloff, G., Iyer, S.P., Maguire, M., Golovko, A., Zeng, M., Wang, L., Murgolo, N., and Graziano, M.P. 2004. Niemann-Pick C1 Like 1 protein is critical for intestinal cholesterol absorption. Science 303(5661): 1201-1204. doi: 10.1126/science.1093131.

Arjmandi, B.H., Ahn, J., Nathani, S., and Reeves, R.D. 1992. Dietary soluble fiber and cholesterol affect serum cholesterol concentration, hepatic portal venous short-chain fatty acid concentrations and fecal sterol excretion in rats. J Nutr 122(2): 246-253.

Bokura, H., and Kobayashi, S. 2003. Chitosan decreases total cholesterol in women: a randomized, double-blind, placebo-controlled trial. Eur J Clin Nutr 57(5): 721-725. doi: 10.1038/sj.ejcn.1601603.

Carroll, K.K. 1991. Review of clinical studies on cholesterol-lowering response to soy protein. J Am Diet Assoc 91(7): 820-827.

Choy, P.C., Siow, Y.L., Mymin, D., and O, K. 2004. Lipids and atherosclerosis. Biochem Cell Biol 82(1): 212-224. doi: 10.1139/o03-085.

Folch, J., Lees, M., and Sloane Stanley, G.H. 1957. A simple method for the isolation and purification of total lipides from animal tissues. J Biol Chem 226(1): 497-509.

Gallaher, C.M., Munion, J., Hesslink, R., Jr., Wise, J., and Gallaher, D.D. 2000. Cholesterol reduction by glucomannan and chitosan is mediated by changes in cholesterol absorption and bile acid and fat excretion in rats. J Nutr 130(11): 2753-2759.

Gonzalez-Granillo, M., Steffensen, K.R., Granados, O., Torres, N., Korach-Andre, M., Ortiz, V., 
Aguilar-Salinas, C., Jakobsson, T., Diaz-Villasenor, A., Loza-Valdes, A., Hernandez-Pando, R., Gustafsson, J.A., and Tovar, A.R. 2012. Soy protein isoflavones differentially regulate liver X receptor isoforms to modulate lipid metabolism and cholesterol transport in the liver and intestine in mice. Diabetologia 55(9): 2469-2478. doi: 10.1007/s00125-012-2599-9.

Gunness, P., and Gidley, M.J. 2010. Mechanisms underlying the cholesterol-lowering properties of soluble dietary fibre polysaccharides. Food Funct 1(2): 149-155. doi: 10.1039/c0fo00080a.

Harmsen, M.C., Swart, P.J., de Bethune, M.P., Pauwels, R., De Clercq, E., The, T.H., and Meijer, D.K. 1995. Antiviral effects of plasma and milk proteins: lactoferrin shows potent activity against both human immunodeficiency virus and human cytomegalovirus replication in vitro. J Infect Dis 172(2): 380-388.

Hoang, M.H., Houng, S.J., Jun, H.J., Lee, J.H., Choi, J.W., Kim, S.H., Kim, Y.R., and Lee, S.J. 2011. Barley intake induces bile acid excretion by reduced expression of intestinal ASBT and NPC1L1 in C57BL/6J mice. J Agric Food Chem 59(12): 6798-6805. doi: 10.1021/jf200681n.

Huth, M., Dongowski, G., Gebhardt, E., and Flamme, W. 2000. Functional Properties of dietary fiber enriched extrudates from barley. Journal of Cereal Science 32(2): 115-128. doi: 10.1006/jcrs.2000.0330.

Ikoma-Seki, K., Nakamura, K., Morishita, S., Ono, T., Sugiyama, K., Nishino, H., Hirano, H., and Murakoshi, M. 2015. Role of LRP1 and ERK and cAMP Signaling Pathways in Lactoferrin-Induced Lipolysis in Mature Rat Adipocytes. PLoS One 10(10): e0141378. doi: 10.1371/journal.pone.0141378.

Kobayashi, M., Unno, T., Suzuki, Y., Nozawa, A., Sagesaka, Y., Kakuda, T., and Ikeda, I. 2005. Heat-epimerized tea catechins have the same cholesterol-lowering activity as green tea catechins in cholesterol-fed rats. Biosci Biotechnol Biochem 69(12): 2455-2458. doi: 10.1271/bbb.69.2455.

Kozu, T., Iinuma, G., Ohashi, Y., Saito, Y., Akasu, T., Saito, D., Alexander, D.B., Iigo, M., Kakizoe, T., and Tsuda, H. 2009. Effect of orally administered bovine lactoferrin on the growth of adenomatous colorectal polyps in a randomized, placebo-controlled clinical trial. Cancer Prev Res (Phila) 2(11): 975-983. doi: 10.1158/1940-6207.CAPR-08-0208.

Kuwata, H., Yamauchi, K., Teraguchi, S., Ushida, Y., Shimokawa, Y., Toida, T., and Hayasawa, H. 2001. Functional fragments of ingested lactoferrin are resistant to proteolytic degradation in the gastrointestinal tract of adult rats. J Nutr 131(8): 2121-2127.

Liang, Y.T., Chen, J., Jiao, R., Peng, C., Zuo, Y., Lei, L., Liu, Y., Wang, X., Ma, K.Y., Huang, Y., and Chen, Z.Y. 2015. Cholesterol-lowering activity of sesamin is associated with down-regulation on genes of sterol transporters involved in cholesterol absorption. J Agric Food Chem 63(11): 2963-2969. doi: 10.1021/jf5063606.

Liu, J., Zhang, J., and Xia, W. 2008. Hypocholesterolaemic effects of different chitosan samples 
in vitro and in vivo. Food Chemistry 107(1): 419-425. doi: 10.1016/j.foodchem.2007.08.044. Liyanage, R., Han, K., Shimada, K., Sekikawa, M., Tokuji, Y., Ohba, K., Sasaki, K., Jayawardama, B.C., Shimazu, T., and Fukushima, M. 2009. Potato and soy peptides alter caecal fermentation and reduce serum non-HDL cholesterol in rats fed cholesterol. European Journal of Lipid Science and Technology 111(9): 884-892. doi: 10.1002/ejlt.200800264. members, E.D.P.o.t.I.A.S.P. 2014. An International Atherosclerosis Society Position Paper: global recommendations for the management of dyslipidemia--full report. J Clin Lipidol 8(1): 29-60. doi: 10.1016/j.jacl.2013.12.005.

Meyerhoffer, M.S., and McGown, B.L. 1990. Critical micelle concentration behavior of sodium taurocholate in water. Langmuir 6(1): 187-191. doi: 10.1021/la00091a030.

Mhurchu, C.N., Poppitt, S.D., McGill, A.T., Leahy, F.E., Bennett, D.A., Lin, R.B., Ormrod, D., Ward, L., Strik, C., and Rodgers, A. 2004. The effect of the dietary supplement, Chitosan, on body weight: a randomised controlled trial in 250 overweight and obese adults. Int J Obes Relat Metab Disord 28(9): 1149-1156. doi: 10.1038/sj.ijo.0802693.

Moreno-Navarrete, J.M., Ortega, F.J., Ricart, W., and Fernandez-Real, J.M. 2009. Lactoferrin increases (172Thr)AMPK phosphorylation and insulin-induced (p473Ser)AKT while impairing adipocyte differentiation. Int J Obes (Lond) 33(9): 991-1000. doi: 10.1038/ijo.2009.143. Morishita, S., Kawaguchi, H., Ono, T., Miura, N., Murakoshi, M., Sugiyama, K., Kato, H., Tanimoto, A., and Nishino, H. 2016. Enteric lactoferrin attenuates the development of high-fat and high-cholesterol diet-induced hypercholesterolemia and atherosclerosis in Microminipigs. Biosci Biotechnol Biochem 80(2): 295-303. doi: 10.1080/09168451.2015.1091713.

Morishita, S., Ono, T., Fujisaki, C., Ishihara, Y., Murakoshi, M., Kato, H., Hosokawa, M., Miyashita, K., Sugiyama, K., and Nishino, H. 2013. Bovine lactoferrin reduces visceral fat and liver triglycerides in ICR mice. J Oleo Sci 62(2): 97-103.

Morishita, S., Tomita, K., Ono, T., Murakoshi, M., Saito, K., Sugiyama, K., Nishino, H., and Kato, H. 2015. Lactoferrin attenuates fatty acid-induced lipotoxicity via Akt signaling in hepatocarcinoma cells. Biochem Cell Biol 93(6): 566-573. doi: 10.1139/bcb-2015-0014. Muramatsu, K., Fukuyo, M., and Hara, Y. 1986. Effect of green tea catechins on plasma cholesterol level in cholesterol-fed rats. J Nutr Sci Vitaminol (Tokyo) 32(6): 613-622. Nagaoka, S., Miwa, K., Eto, M., Kuzuya, Y., Hori, G., and Yamamoto, K. 1999. Soy protein peptic hydrolysate with bound phospholipids decreases micellar solubility and cholesterol absorption in rats and caco-2 cells. J Nutr 129(9): 1725-1730.

Ono, T., Fujisaki, C., Ishihara, Y., Ikoma, K., Morishita, S., Murakoshi, M., Sugiyama, K., Kato, H., Miyashita, K., Yoshida, T., and Nishino, H. 2013. Potent lipolytic activity of lactoferrin in mature adipocytes. Biosci Biotechnol Biochem 77(3): 566-571. doi: 10.1271/bbb.120817.

Ono, T., Morishita, S., Fujisaki, C., Ohdera, M., Murakoshi, M., Iida, N., Kato, H., Miyashita, 
K., Iigo, M., Yoshida, T., Sugiyama, K., and Nishino, H. 2011. Effects of pepsin and trypsin on the anti-adipogenic action of lactoferrin against pre-adipocytes derived from rat mesenteric fat. Br J Nutr 105(2): 200-211. doi: 10.1017/S0007114510003259.

Ono, T., Murakoshi, M., Suzuki, N., Iida, N., Ohdera, M., Iigo, M., Yoshida, T., Sugiyama, K., and Nishino, H. 2010. Potent anti-obesity effect of enteric-coated lactoferrin: decrease in visceral fat accumulation in Japanese men and women with abdominal obesity after 8-week administration of enteric-coated lactoferrin tablets. Br J Nutr 104(11): 1688-1695. doi: 10.1017/S0007114510002734.

Roy, S. 2014. Atherosclerotic Cardiovascular Disease Risk and Evidence-based Management of Cholesterol. N Am J Med Sci 6(5): 191-198. doi: 10.4103/1947-2714.132916.

Shoji, H., Oguchi, S., Shinohara, K., Shimizu, T., and Yamashiro, Y. 2007. Effects of iron-unsaturated human lactoferrin on hydrogen peroxide-induced oxidative damage in intestinal epithelial cells. Pediatr Res 61(1): 89-92. doi: 10.1203/01.pdr.0000250198.22735.20. Siow, Y., Schurr, A., and Vitale, G.C. 1991. Diabetes-induced bile acid composition changes in rat bile determined by high performance liquid chromatography. Life Sci 49(18): 1301-1308.

Takeuchi, T., Shimizu, H., Ando, K., and Harada, E. 2004. Bovine lactoferrin reduces plasma triacylglycerol and NEFA accompanied by decreased hepatic cholesterol and triacylglycerol contents in rodents. Br J Nutr 91(4): 533-538. doi: 10.1079/BJN20041090.

Tomita, M., Bellamy, W., Takase, M., Yamauchi, K., Wakabayashi, H., and Kawase, K. 1991. Potent antibacterial peptides generated by pepsin digestion of bovine lactoferrin. J Dairy Sci 74(12): 4137-4142. doi: 10.3168/jds.S0022-0302(91)78608-6.

Tomita, M., Wakabayashi, H., Shin, K., Yamauchi, K., Yaeshima, T., and Iwatsuki, K. 2009. Twenty-five years of research on bovine lactoferrin applications. Biochimie 91(1): 52-57. doi: 10.1016/j.biochi.2008.05.021.

Vogel, H.J. 2012. Lactoferrin, a bird's eye view. Biochem Cell Biol 90(3): 233-244. doi: 10.1139/o2012-016.

Wilson, M.D., and Rudel, L.L. 1994. Review of cholesterol absorption with emphasis on dietary and biliary cholesterol. J Lipid Res 35(6): 943-955.

Yagi, M., Suzuki, N., Takayama, T., Arisue, M., Kodama, T., Yoda, Y., Numasaki, H., Otsuka, K., and Ito, K. 2008. Lactoferrin suppress the adipogenic differentiation of MC3T3-G2/PA6 cells. J Oral Sci 50(4): 419-425.

Zimecki, M., Wlaszczyk, A., Cheneau, P., Brunel, A.S., Mazurier, J., Spik, G., and Kubler, A. 1998. Immunoregulatory effects of a nutritional preparation containing bovine lactoferrin taken orally by healthy individuals. Arch Immunol Ther Exp (Warsz) 46(4): 231-240. 


\section{Figure captions}

Fig. 1. Interaction between LF and taurocholate in vitro

LF (pI 8.2 to 8.9 ) or transferrin (pI 5.2 to 6.3 ) was incubated with $0.5 \mathrm{mg} / \mathrm{mL}$ sodium taurocholate in phosphate buffer $(\mathrm{pH} 6.5)$ at $37^{\circ} \mathrm{C}$ for $2 \mathrm{~h}$. A decrease in taurocholate after ultrafiltration (MWCO 10K) was determined and showed as taurocholate bound (\%). Values are expressed as means \pm standard deviations $(n=4)$. Statistical analysis was performed using one-way ANOVA followed by the post-hoc Tukey-Kramer test. Different letters (a, b, c) indicate significant differences between groups $(p<0.05)$.

Fig. 2. Correlation between hepatic cholesterol and excretion levels of fecal neutral steroids HCD group, $(\bigcirc)$ and HCD + LF group,

Data were analyzed using the Pearson product-moment correlation coefficient. 
Table 1. Composition of the basal diet

\begin{tabular}{lcc}
\hline Ingredient & \multicolumn{2}{c}{ Basal Diet } \\
\hline & $(\mathrm{g})$ & $(\mathrm{kcal})$ \\
Casein & 200.0 & 800 \\
L-Cystine & 3.0 & 12 \\
Corn Starch & 290.0 & 1160 \\
Maltodextrin 10 & 100.0 & 400 \\
Sucrose & 100.0 & 400 \\
Soybean Oil & 132.0 & 1188 \\
Vitamin Mix V10037 & 10.0 & 40 \\
Mineral Mix S10022G & 35.0 & \\
Choline Bitartrate & 2.5 & \\
t-Butylhydroquinone & 0.026 & \\
Cellulose & 50.0 & \\
Total & 922.5 & 4000 \\
\hline
\end{tabular}


Table 2. Composition of experimental diets

\begin{tabular}{lccc}
\hline & Control & HCD & HCD + LF \\
\hline & & $(\mathrm{g})$ & \\
Basal Diet & 1000 & 1000 & 1000 \\
Cholesterol & & 3 & 3 \\
Casein & 50 & 50 & \\
LF & & & 50 \\
Total & 1050 & 1053 & 1053 \\
\hline
\end{tabular}


Table 3. LF levels in the proximal halves of the small intestine after oral administration

\begin{tabular}{llcccc}
\hline & Control & \multicolumn{4}{c}{ Time after LF administration } \\
\cline { 2 - 5 } & & $7.5 \mathrm{~min}$ & $15 \mathrm{~min}$ & $30 \mathrm{~min}$ & $60 \mathrm{~min}$ \\
\hline LF (mg/proximal intestine) & N.D. $^{*}$ & $1.5 \pm 1.7$ & $0.14 \pm 0.11$ & $0.094 \pm 0.061$ & $0.033 \pm 0.025$ \\
\hline *N.D.; Not detected. Detection limit & is $0.0041 \mathrm{mg}$ in & the proximal & intestine. Values are \\
expressed as means \pm standard deviations (Control group; $\mathrm{n}=4$, LF administration group; $\mathrm{n}=$ \\
6).
\end{tabular}


Table 4. Body weight and food intake during the experimental period

\begin{tabular}{lccc}
\hline & Control & HCD & HCD + LF \\
\hline Initial body weight $(\mathrm{g})$ & $241 \pm 7$ & $240 \pm 7$ & $240 \pm 5$ \\
Final body weight $(\mathrm{g})$ & $411 \pm 15$ & $395 \pm 23$ & $407 \pm 12$ \\
Weight gain $(\mathrm{g})$ & $171 \pm 10$ & $155 \pm 19$ & $166 \pm 10$ \\
Food intake $(\mathrm{g} / \mathrm{d})$ & $23.3 \pm 1.1$ & $21.5 \pm 1.7$ & $22.4 \pm 1.4$ \\
\hline
\end{tabular}

Values are expressed as means \pm standard deviations $(n=8)$. Data were analyzed using one-way ANOVA. 
Table 5. Serum total cholesterol, triglyceride, and hepatic cholesterol levels

\begin{tabular}{|c|c|c|c|c|c|c|c|c|c|}
\hline Serum & \multicolumn{3}{|c|}{ Control } & \multicolumn{3}{|c|}{$\mathrm{HCD}$} & \multicolumn{3}{|c|}{$\mathrm{HCD}+\mathrm{LF}$} \\
\hline Total cholesterol (mg/dl) & 94.4 & \pm & 15.5 & 103 & \pm & 16 & 99.7 & \pm & 16.6 \\
\hline Triglyceride (mg/dl) & 139 & \pm & 64 & 222 & \pm & 56 & 195 & \pm & 86 \\
\hline Hepatic cholesterol ( $\mu \mathrm{mol} / \mathrm{g}$ liver) & 9.10 & \pm & $0.93^{\mathrm{a}}$ & 59.1 & \pm & $4.9^{\mathrm{b}}$ & 48.9 & \pm & $10.1^{\mathrm{c}}$ \\
\hline
\end{tabular}


Table 6. Fecal weight and steroid excretion levels during the last 2 days of the feeding period

\begin{tabular}{lccc}
\hline & Control & HCD & HCD + LF \\
\hline Fecal weight $(\mathrm{g} / \mathrm{d})$ & $1.73 \pm 0.22$ & $1.77 \pm 0.14$ & $1.84 \pm 0.26$ \\
Fecal steroid excretion & & & \\
Bile acids $(\mu \mathrm{mol} / \mathrm{d})$ & $10.6 \pm 1.6^{\mathrm{a}}$ & $31.5 \pm 4.7^{\mathrm{b}}$ & $32.5 \pm 6.0^{\mathrm{b}}$ \\
Neutral steroids $(\mu \mathrm{mol} / \mathrm{d})$ & $20.3 \pm 3.0^{\mathrm{a}}$ & $74.7 \pm 9.2^{\mathrm{b}}$ & $91.5 \pm 17.0^{\mathrm{c}}$ \\
$\quad$ Coprostanol $(\mu \mathrm{mol} / \mathrm{d})$ & $9.81 \pm 2.19^{\mathrm{a}}$ & $28.4 \pm 8.1^{\mathrm{b}}$ & $29.8 \pm 7.6^{\mathrm{b}}$ \\
Cholesterol $(\mu \mathrm{mol} / \mathrm{d})$ & $10.5 \pm 3.1^{\mathrm{a}}$ & $46.3 \pm 8.6^{\mathrm{b}}$ & $61.7 \pm 17.5^{\mathrm{c}}$ \\
\hline
\end{tabular}

Values are expressed as means \pm standard deviations $(n=8)$. Data were analyzed using one-way ANOVA and the post-hoc Tukey-Kramer test. Different superscript letters (a, b, c) in each outcome indicate significant differences between groups $(p<0.05)$. 


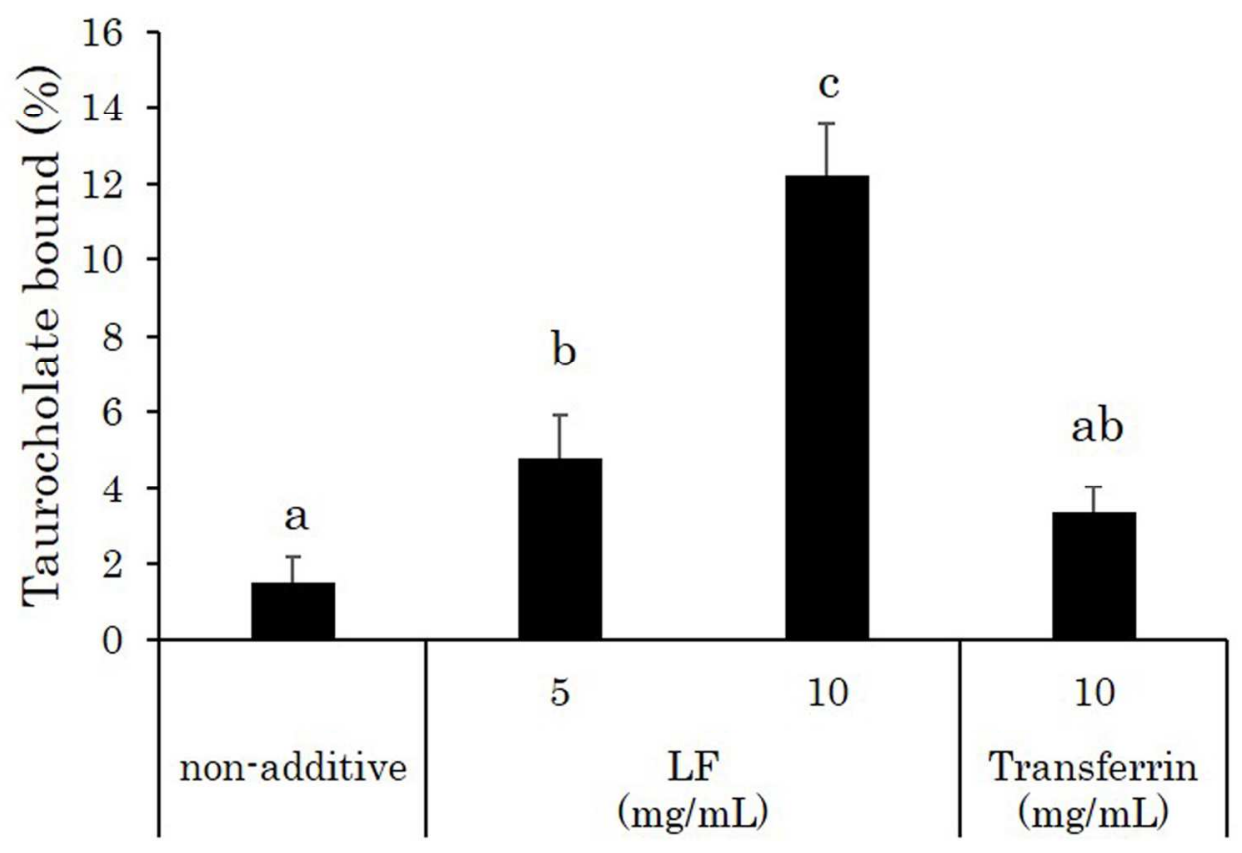

Fig. 1. Interaction between LF and taurocholate in vitro

LF (pI 8.2 to 8.9) or transferrin ( $\mathrm{pI} 5.2$ to 6.3 ) was incubated with $0.5 \mathrm{mg} / \mathrm{mL}$ sodium taurocholate in phosphate buffer $\left(\mathrm{pH} \mathrm{6.5)}\right.$ at $37^{\circ} \mathrm{C}$ for $2 \mathrm{~h}$. A decrease in taurocholate after ultrafiltration (MWCO 10K) was determined and showed as taurocholate bound (\%). Values are expressed as means \pm standard deviations $(n=4)$. Statistical analysis was performed using one-way ANOVA followed by the post-hoc Tukey-Kramer test. Different letters $(a, b, c)$ indicate significant differences between groups $(p<0.05)$.

$128 \times 85 \mathrm{~mm}(300 \times 300 \mathrm{DPI})$ 


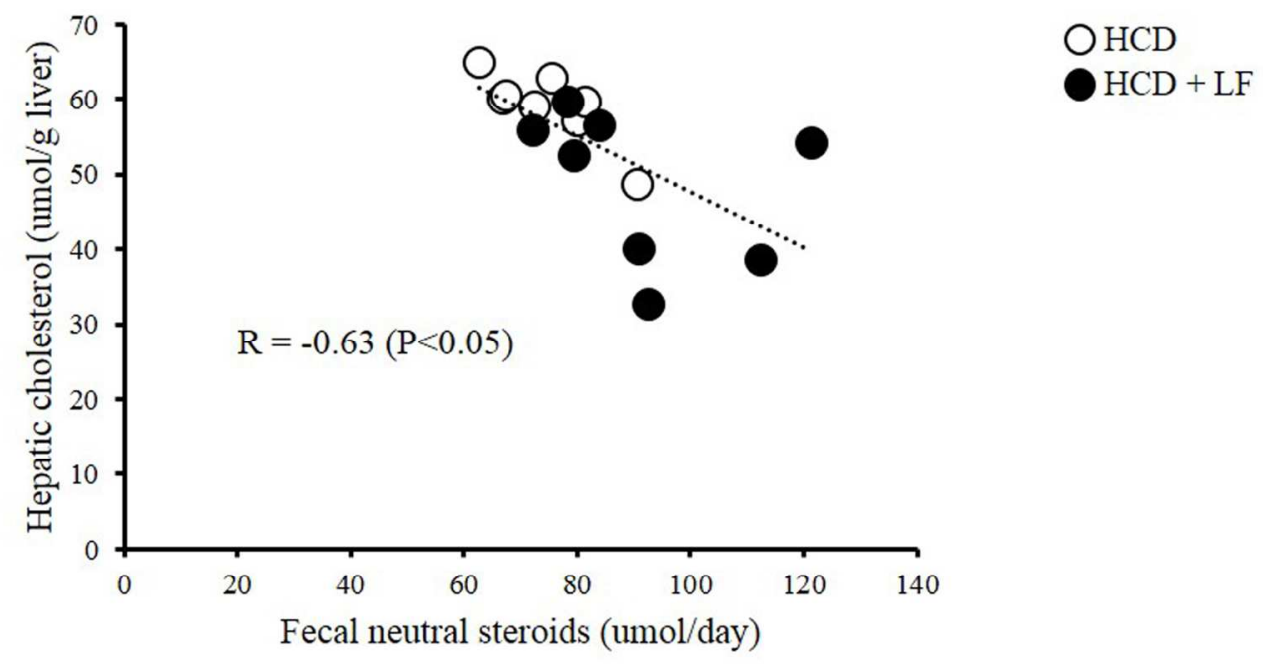

Fig. 2. Correlation between hepatic cholesterol and excretion levels of fecal neutral steroids HCD group, (०) and HCD + LF group, $(\bullet)$

Data were analyzed using the Pearson product-moment correlation coefficient.

$139 \times 75 \mathrm{~mm}(300 \times 300$ DPI $)$ 